\title{
Bifidobacterium pseudocatenulatum
}

National Cancer Institute

\section{Source}

National Cancer Institute. Bifidobacterium pseudocatenulatum. NCI Thesaurus. Code C122249.

A bacterial species in the family Bifidobacteriaceae. B. pseudocatenulatum hydrolyzes phytate and ferments amylopectin and amylose and does not ferment D-galactosamine, D-glucuronate, arabinogalactan, pectin, or gums. This bacteria is a normal part of the gut flora and is frequently used as a probiotic. 